Gomes D., Tzortzopoulos P., and Kagioglou M. (2017). "Socio-constructivist Account of Collaboration in Concept Design.” In: LC3 2017 Volume II - Proceedings of the 25th Annual Conference of the International Group for Lean Construction (IGLC), Walsh, K., Sacks, R., Brilakis, I. (eds.), Heraklion, Greece, pp. 301-308. DOI: https://doi.org/10.24928/2017/0300

\title{
SOCIO-CONSTRUCTIVIST ACCOUNT OF COLLABORATION IN CONCEPT DESIGN
}

\author{
Danilo Gomes ${ }^{1}$, Patrícia Tzortzopoulos ${ }^{2}$, and Mike Kagioglou ${ }^{3}$
}

\begin{abstract}
In a collective design situation, participants usually have limited understanding of how other designers operate in the project and how their work has interdependencies with other design tasks. Most commonly, misunderstandings between team members will emerge around vague design representations and undocumented decisions, creating negative iterations in design. Collaboration at concept design includes actions to build shared understanding of product and process concepts amongst the design team. In this paper, it is suggested that the wicked nature of concept design requires collaboration to be conceptualised in terms of collective creative actions within team interactions. Through a synthesis of the literature, a model to study collaboration in concept design is suggested. The model proposes that collaboration is determined by the group's ability to perform collective-reflective actions. Further development on the proposed model will provide ways of measuring and improving collaboration within multidisciplinary design teams.
\end{abstract}

Keywords: Collaboration, Multidisciplinary Team, Concept Design, Shared Understanding, Socio-constructive interactions

\section{INTRODUCTION}

The concept design stage, referred to as Project Definition in the Lean Project Delivery (Ballard, 2008), consists of determining a concept design based on the identification and translation of project requirements into performance criteria for both product and process, developed by a multidisciplinary team. However, during concept design, designers usually have limited understanding of how other designers operate in the project and how their work has interdependencies with others (Cross and Cross, 1995; Arias et al., 2000). In some cases, in order to eliminate ambiguity in the informal exchange, the project team is co-located (Paranandi, 2014). However, to work co-located is generally not sufficient to solve the issue, and the lack of integration on decisionmaking can still happen as misunderstandings between team members around vague design representations and undocumented decisions (Maher et al., 1996). These misunderstandings occur due to different languages, standards, and wrong assumptions between design disciplines (Parrish et al., 2008). Consequently, team members cannot realise the consequences of incompatible decisions at the time, which can hamper later activities, creating negative design interactions and causing unnecessary iterative loops (Valkenburg, 1998).

PhD candidate in Architecture, University of Huddersfield, UK danilo.gomes@hud.ac.uk

Professor, Head of Department for Architecture and 3D Design, University of Huddersfield, UK, p.tzortzopoulos@hud.ac.uk

Professor, Dean of the School of Art, Design and Architecture, University of Huddersfield, UK, m.kagioglou@hud.ac.uk 
From a theoretical point of view, there seems to be tension between the idea of the team and individual within design (Coyne and Snodgrass, 1993; Dorst, 2006). According to these authors, collaboration in design is usually seen as an activity in which individuals come together to share their skills and insights, in way that benefits are derived from the collection of the private skills and insights of individuals. Alternatively, it can be argued that human activity is 'collaborative' by nature, whether we are aware of it or not, involving a collective shared experience that is much more than the collection of individuals knowledge (Coyne and Snodgrass, 1993).

Researchers have argued that traditional models of design activity fail to realise the social constructive nature of collaborative design (Coyne and Snodgraas, 1993; Dorst, 2006). The social construction theory suggest that reality is not objectively given, but rather, constructed through social interactions generating interpretations, as collective meanings, that emerging from conversations among individuals in the social space (Gergen, 1985). In this context, professional expertise, technical competence, and skills should not be seen as a commodity for individuals, but rather existing within a community (Schön, 1983; Coyne and Snodgrass, 1993, Dorst, 2006).

The aim of this paper is to present a collaborative concept design model, seen as a socio-constructive action. This model offers a conceptual framework to investigate and measure collaborative concept design in practical situations. Further steps in this research requires the application of the model on multiple cases studies.

\section{Collaborative Design as Social Construction}

Traditional design process models have been proposed as derivation from theories belonging to the logical-empirical sciences (i.e. Science of Artificial from Herbert Simon, 1969), and are deeply rooted in the Cartesian ontology, aligning them to a mathematical problem to be solved by way of prescribed logical steps (Snodgrass and Coyne, 1992; Dorst, 2006). The main assumption embedded in such design process models is that they offer logically coherent and consistent structures, which consequently, could be logically deducible, and logically expressible (Snodgrass and Coyne, 1992). However, the methodological description of design activities as "design problem" is very problematic or even meaningless to say if we cannot define it or crystalise it in empirical descriptions (Dorst, 2006).

According to Snodgrass and Coyne (1992), Dorst and Dijkhuis (1995), Lloyd and Busby (2001) and Dorst (2006), a more appropriate model of design activity was proposed by Schön (1983) conceptualising design as reflective activity, and replacing the logic-based models that have driven traditional design research. In this model (figure 1), designing is experimentation, and design moves can be seen as actions to test hypothesis and explore a phenomena, either affirming or negating that move (Schön, 1983). The evaluation of the performance of the hypothesis will be based on the way the designer framed the situation setting a particular perspective of the problem to be solved. When designers evaluate how design moves affects the framed situation, they establish a conversational process in which the situation 'talks back', allowing them to see it differently and constantly constructing new meanings and intentions (Schon, 1984).

More importantly, in a collective design situation, each participant sees the object of design differently, based on their position of responsibility and, more importantly, on the paradigmatic nature of their discipline (Bucciarelli, 2003). This means that nobody will have a total understanding of the object and process of design. Therefore, the design task cannot be fully disaggregated or reduced to subtasks that can be independently pursued, 
and demands actions for reconciling and harmonising claims, requirements and proposals of different participants, in a process that evolves through discussion and negotiation across object worlds (Bucciarelli, 2003).

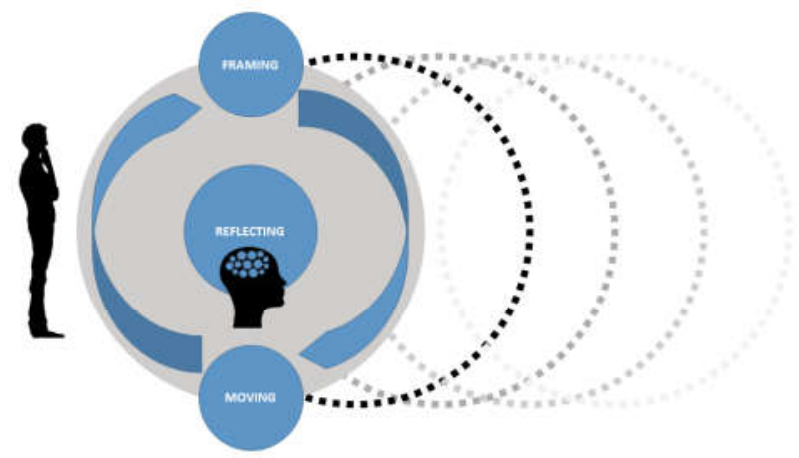

Figure 1: Dynamics of Design Situation as suggested by Schön (1983)

In this context, shared understanding is a social phenomenon, towards the suppression of differences in interpretation and conformity in the collective act (Coyne and Snodgrass, 1993). All understanding and action is based on a background of experiences that exist in a context of shared cultural practices (Coyne and Snodgrass, 1993). The matter of interpretation and the validity of the assessment over design actions will be influenced by skills of judgment and the experience in understanding the unique situation, and not about knowledge of rules or algorithmic formulae (Snodgrass and Coyne, 1992). Therefore, agreement on the assessment of the validity of a model will be reached through argumentation and persuasion between team members (Snodgrass and Coyne, 1992).

More precisely, shared understanding would be deeply rooted in a collective process of reflection upon design moves within the shared context of the design activity supporting the integration of various perspectives (Arias et al., 2000). Consequently, collaborative design would be a situation in which stakeholders and experts could reason directly about emergent conflicts and collectively work towards new perspectives to mitigate it (Craig and Zimring, 2002). According to these authors, the effects of a collaborative approach in design is to allow collective reflection-in-action (Schön, 1983), in which collaborators help each other to discover the unintended consequences of design moves.

Therefore, collaborative design can be defined as a situation of shared creation, in which the collection of agents with complementary skills interact to create a shared understanding about a process, a product or an event that does not pre-exist that collective situation (Schrage, 1995), which fits to the Project Definition phase in Lean Project Delivery. Following this conceptualization, and expanding on Schön's initial model of design activity, it is suggested that collaborative design exists in terms of skilful team interactions for social construction of meaning involving three complementary efforts: collective appreciation, collective representation and reflective dialogue. These are described as follows. 


\section{COllaborative Design as CREATIVE INTERACTION}

\subsection{Collective Appreciation}

Designers will differ from one another in respect to design judgments and ways of framing problems, coming to interact with different perspectives and systems of appreciation (Schon, 1984). It seems that, to be aware of and eventually overcome a conflict of appreciation, require from designers to carry a specific sort of collective inquiry, which eventually can reveal both the intractability of their dilemma and an alternative approach to the design solution (Schon, 1984). These design experimentations can only reach objectivity within the framework of an appreciative system, which considers the designers preferences, values, likings, meanings and norms (Schön, 1984).

According to Vickers' Theory of Appreciative Systems, appreciation is occasioned by an ability to perceive and make judgments that contributes to the ideas stream leading to actions that also become part of the events stream (Vickers, 1965 apud Checkland, 1994). Moreover, in collaborative design, this appreciative ability can be related to the concept of team situational awareness proposed by Endsley (1995). According to this author, situation awareness is the capacity to perceive and comprehend the characteristics of an environment in a specific set of time and space supporting the realisation of predicted futures aligned with a task or project. As an ability this would be intrinsically related to what each worker knows about the understanding and workload of the co-worker, and how this is supported by intercommunication between them (Endsley and Jones, 2001).

\subsection{Collective Representation}

Collaborative actions deal with the process of searching for common representations of proposed course of actions (Qu and Hansen, 2008), and graphical or physical artefacts are the usual means to embody such reasoning in design (Fischer, 2004). It is more than a simple aggregation of individuals and involves discussing and negotiating representations' structure to achieve a level of consensus. Since the coupling of representations and understanding cannot be assumed, a collective effort is necessary to support change in each collaborator's internal representation and meaning, to come to a collectively constructed representation comprising shared understanding ( $\mathrm{Qu}$ and Hansen, 2008).

The process of building shared understanding forces the collision of ideas, and external representations are the means of negotiation, in which the objective must be to reach consensus on the meaning of the representations ( $\mathrm{Qu} \&$ Hansen, 2008). The purpose of these shared artefacts should be to provide concrete means of representing different functional interest (Carlile, 2004). The need to synthesise different perspectives of a problem in the evolving nature of a designed artefact is key for designers to collectively understand the consequences of design decisions (Arias et al., 2000).

More importantly, this suggest that what is usually considered relevant design knowledge as a synthesis of expertise from different contributors, cannot be considered existent previously and cannot simply be transferred by those who have it to those who need it (Arias et al., 2000). As described earlier, design involves a collective construction of meaning, in which the concept of shared understanding replaces the idea of knowledge sharing in organisations as suggested by Nonaka (1994).

More recently, based on the work of Ludwig Wittgenstein (1967, apud Smart, 2011), Smart (2011) suggest that understanding is an ability to provide predictive and explanatory grasp on the phenomena that is to be understood, enabling the agent to 
express thoughts and actions that fit the realisation of goals. Accordingly, this is related to an ability that is highly flexible, adaptive and context-sensitive, and often referred as 'knowledge in use' or tacit knowledge. Furthermore, the author suggest that, in a collective effort, shared understanding would imply similarity of understanding in relation to a particular phenomenon (i.e. goals, task, situation), involving the emergence of group abilities to form common expectations and predictions regarding future states, actions, events.

This ability to form expectations and predictions of future states and actions is intrinsically embedded in the nature of design representation. Consequently, to recognise this nature of shared artefacts in design, as collective actions of modelling shared understanding, essentially challenges the Kantian epistemology in which knowledge is perceived as a thing (Snowden, 2002). This assumption aligns with the heuristic approach to knowledge, suggested by Snowden (2002), in which knowledge should be considered simultaneously as: only volunteered and not conscripted; reflective in a way that it arguably dissociated from our capacity to externalise it; and contextual, as it is triggered by circumstance.

\subsection{Reflective Dialogue}

In design teams, practitioners need to recognise that individual technical expertise only exist embedded in a context of meanings, in which meaningful interactions would be generally related to the surfacing of negative information, the public negotiation of dilemmas and the resolution or dissolution of conflicting views (Schön, 1983). Accordingly, this reciprocal reflection-in-action emerges as a reflective conversation, establishing a "learning system" that is conditioned by the organisational structure and behavioural culture (Schön, 1983).

Conversations take place over a bedrock of common assumptions and experiences, allowing participants to interact without extensive explanations (Lloyd and Busby, 2001). Common assumptions usually refer to technical properties of a design solution, and common experiences relates to past events or facts that contextualise the current situation (Lloyd and Busby, 2001). Both can be seen as discursive objects (i.e. mediating artefacts), serving as objective reference for interpreting the situation.

Lloyd and Busby (2001) identified that conflicts often happen over the consequences of certain "facts" in an evolving situation. In these occasions, the designers put their technical skills second and displayed a set of skills to make a convincing interpretation of the situation. Designers show skills to construct an effective argument to get their version of the consequences on a situation accepted in a meeting (Lloyd and Busby, 2001). Using language mechanisms of engagement, exaggeration and imagery, designers try to create situations of implied objectivity over common assumptions and/or past experiences, as a rhetorical ability to build argumentation (Lloyd and Busby, 2001).

More recently, Koskela (2015) explored the relation between lean principles and the discipline of rhetoric. Accordingly, rhetoric works as means for human productive interaction, in which persuasion acts towards compliance (i.e. collective design decisions). Conversations are developed based on the existence of a common ground, as a set of common values, mutually known facts, and commonly held presumptions between agents from different backgrounds (Koskela, 2015). Therefore, as well as graphic representations assume a modelling role in design discussions, words can also provide a kind of collective sketching function that remains ambiguous while suggesting possibilities, providing a first level of prototyping in the collective action of design (Lloyd and Busby, 2001). 


\section{COLLABORATIVE CONCEPT DESIGN MODEL}

Our definition of collaborative concept design considers Schrage's (1995) definition of collaboration presented earlier, and the socio-constructivist account of collaborative design presented in terms of specific skilful team collective actions presented in the last section. Hence, collaborative concept design can be defined as a collective creative situation, in which a multidisciplinary team collectively contribute in the representation activity to compromise on design decisions while being collectively aware of the consequences of those decisions.

However, this socio-constructivist account of collaborative concept design suggest the expansion of the metaphor proposed by Schon (1983) to a new one that includes three modes of action that emerge from the interaction of the collection of individuals (i.e. the team) as: collective appreciation, collective representation and reflective dialogue (Figure 2).

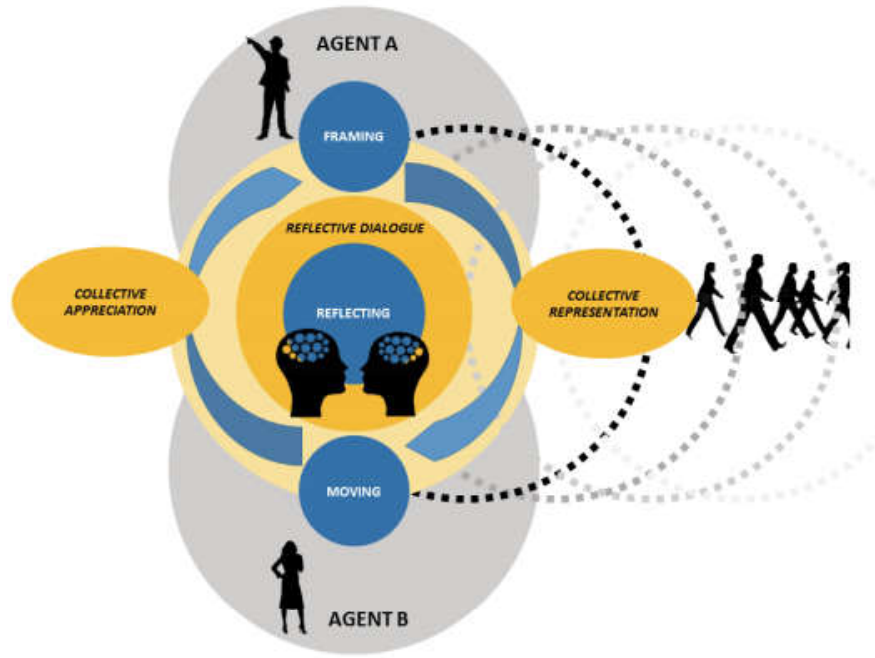

Figure 2: Model of Collaborative Concept Design Dynamics

In this model, the three modes of action (framing, moving, reflection), suggested by Schön (1983) remain as the motion trigger of the design situation, while the new three "lateral" actions function to converge the diverse reasoning processes of the team, work as a "gravitational force" generated by the collective engagement on design actions. A deeper exploration on the nature of those actions and their respective functions is still needed in order to understand how they relate to abilities to effectively perform collaborative design.

\section{CONCLUSIONS}

Focusing on the negative iterations in concept design caused by misunderstandings between team members, this study offers a new conceptualisation of collaborative concept design. This suggests that collaboration, as design collective creative action, is dependent on the team ability to develop shared understanding among the participants, through a dynamic process of social construction of meaning.

The model proposed indicates that the dynamics of this process involve three modes collective of actions: collective appreciation, collective representation and reflective dialogue. Each of them is based on a specific set of skills that usually are considered as 
"tacit knowledge". However, we argued that the concept of shared understanding is more appropriate to define the socio-constructive nature of design actions. More specifically, we suggest that the key element on this dynamic model is how the design team collectively articulate interdependencies during concept design, while they collectively move around different modes of action. Deepening our understanding of the nature and the circumstances of those collective actions would help to establish measures for collaborative design interactions and to suggest improvement strategies for collaborative practices in design.

The measures of collaborative design performance start by questioning how the three modes of action suggested in the model operate, focusing on how team members collectively articulate interdependencies: how much of the design decisions, graphically or verbally represented, have the involvement of the "key players" in the situation (Collective Representation); how design decisions take into consideration the appreciative systems of the team members (Collective Appreciation); and how designers are able to engage in reflective conversations, to expand or negotiate the collection of interpretations and representations supporting decision-making (Reflective Dialogue).

Further investigation on the usability of those measures and of the proposed model will be developed through case studies in different collaborative concept design practices.

\section{REFERENCES}

Arias, E., Eden, H., Fischer, G., Gorman, A., and Scharff, E. (2000). "Transcending the individual human mind-creating shared understanding through collaborative design". ACM Transactions on Computer-Human Interaction (TOCHI), 7(1), 84-113.

Ballard, G. (2008). "The lean project delivery system: An update". Lean Construction Journal, 2008, 1-19.

Bertelsen, S. (2003). "Construction as a complex system." In Proc. 11rd Ann. Conf. of the Int'l. Group for Lean Construction. Blacksburg, VA, 1-.

Bucciarelli, L. L. (2003). "Designing and learning: a disjunction in contexts". Design Studies, 24(3), 295-311.

Carlile, P. R., (2004). "Transferring, Translating, and Transforming: An Integrative Framework for Managing Knowledge Across Boundaries.” Organization Science. Vol. 15, No. 5, September-October, 555-568.

Checkland, P. (1994). "Systems theory and management thinking". American Behavioral Scientist, 38(1), 75-91.

Coyne, R., and Snodgrass, A. (1993). "Cooperation and individualism in design". Environment and Planning B: Planning and Design, 20(2), 163-174.

Craig, D. L., and Zimring, C. (2002). "Support for collaborative design reasoning in shared virtual spaces". Automation in construction, 11(2), 249-259.

Cross, N., and Cross, A. C. (1995). "Observations of teamwork and social processes in design.” In: Design studies, 16(2), 143-170.

Dorst, K., and Dijkhuis, J. (1995). "Comparing paradigms for describing design activity". Design Studies, 16(2), 261-274.

Dorst, K. (2006). "Design problems and design paradoxes". Design issues,22(3), 4-17.

Endsley, M. R. (1995). "Toward a theory of situation awareness in dynamic systems." In: The Journal of the Human Factors and Ergonomics Society, 37(1), 32-64.

Endsley, M. R., and Jones, W. M. (2001). "A model of inter-and intrateam situation awareness: Implications for design, training and measurement." In: New trends in 
cooperative activities: Understanding system dynamics in complex environments,7,46-67.

Fischer, G. (2004). Social creativity: turning barriers into opportunities for collaborative design. In Proceedings of the eighth conference on Participatory design: Artful integration: interweaving media, materials and practices. Vol. 1 (pp. 152-161). ACM.

Gergen, K. J. (1985). "The social constructionist movement in modern psychology". American psychologist, 40(3), 266-275.

Koskela, L., (2015). "Where rhetoric and lean meet." In: Proc. 23rd Ann. Conf. of the Int'l. Group for Lean Construction, Perth, Australia. 527-535.

Lloyd, P., \& Busby, J. (2001). "Softening up the facts: engineers in design meetings". Design issues, 17(3), 67-82.

Maher, M. L., Cicognani, A., and Simoff, S. (1996). "An experimental study of computer mediated collaborative design.” In: Enabling Technologies: Infrastructure for Collaborative Enterprises. Proceedings of the 5th Workshop. 268-273.

Nonaka, I. (1994). "A dynamic theory of organizational knowledge creation". Organization science, 5(1), 14-37.

Paranandi, M. (2014). "BIM as a Catalyst to Foster Creativity through Collaboration". Building Information Modeling: BIM in Current and Future Practice, 237-249.

Parrish, K., Wong, J. M., Tommelein, I. D., and Stojadinovic, B. (2008). "Set-based design: case study on innovative hospital design.” In: Proc. 16th Ann. Conf. of the Int'l Group for Lean Construction, Manchester, UK, 413-424.

Qu, Y., and Hansen, D. L. (2008). "Building shared understanding in collaborative sensemaking”. In: Proceedings of CHI 2008 Sensemaking Workshop, Florence, Italy.

Rittel, H. W. (1987). "The reasoning of designers". Montreal: IGP.

Schön, D. A. (1983). "The reflective practitioner: How professionals think in action" (Vol. 5126). Basic books.

Schön, D. A. (1984). "Problems, frames and perspectives on designing". Design Studies, 5(3), 132-136.

Schrage, M. (1995). "No more teams! Mastering the dynamics of creative collaboration".

Simon, H. A. (1969). "The sciences of the artificial". Cambridge, MA.

Smart, P.R. (2011). "Understanding and shared understanding in military coalitions". Technical report available at http://eprints.soton.ac.uk/267735/1/suwcv2.pdf

Snodgrass, A., and Coyne, R. (1992). "Models, metaphors and the hermeneutics of designing". Design Issues, 9(1), 56-74.

Snowden, D. (2002). "Complex acts of knowing: paradox and descriptive selfawareness". Journal of knowledge management, 6(2), 100-111.

Valkenburg, R. C. (1998). "Shared understanding as a condition for team design." In: Automation in construction, 7(2), 111-121. 